\title{
MAKE USE OF SELFIE DATA TO GENERATE TARGETED RECOMMENDATIONS FOR SCHOOL TEAMS: TWO INSTRUMENTS
}

\author{
Irina Dvoretskaya ${ }^{1,2}$ and Alexander Uvarov ${ }^{1,2}$ \\ ${ }^{l} F R C$ «Computer Science and Control», Russian Academy of Science, Russia \\ ${ }^{2}$ Institute of Education, Higher School of Economics, Russia
}

\begin{abstract}
As SELFIE (Self-reflection tool for digitally capable schools) piloting has shown, self-assessment of the use of digital technologies (DT) in schools provides school teams with a lot of useful information. Nevertheless, as the feedback highlights, school team members are very interested in also getting the specific targeted recommendations for improving work planning in this area. Here we suggest two practical data-driven approaches for preparing such scale-based recommendations.

The first tool is based on Kruskal-Wallis non-parametric test of responses and helps to evaluate if the school develops and supports the shared vision on the integration of DT in the school. It allows us to correspond to the dichotomous scale of a shared vision. It was found out that on the sample level the influence of the shared vision formation is not tangible. The second tool helps to classify across the sample schools, the progress in the use of innovative teaching and learning with DT. Each school was attributed based on the variability of teachers' and school leaders' responses. A cluster analysis was implemented to classify results. Ten clusters obtained were assigned to three out of five levels of the RISC (Reinventing School Coalition) metric/scale.
\end{abstract}

\section{KEYWORDS}

Self-Assessment Data, Cluster Analysis, Digital Capacity of Schools, Shared Vision, Digital Transformation of Education

\section{INTRODUCTION}

SELFIE (Self-reflection tool for digitally capable schools) is an online platform that provides assessment and insights of how digital technologies are used in the educational process through the eyes of its participants (Munoz Castano et al., 2018). Survey respondents of SELFIE are school leaders, teachers and students, to whom a special questionnaire is assigned, based on DigCompOrg model (Kampylis, Punie and Devine, 2015). As a result of processing the anonymous survey, each school gets an automatically generated report that indicates the average response rates. It is accepted that the teaching staff will use the report to analyze and discuss evidence-based strategies for improvement of their schools.

Schools for the study were chosen from IITE and UNESCO Associated Schools Project Network (UNESCO ASP), within the scope of the SELFIE pilot project in which Russia took part in October 2017. The pilot in Russia was conducted by UNESCO IITE. Three samples were surveyed: school principals $(\mathrm{N}=206)$, school teachers $(\mathrm{N}=685)$, and students $(\mathrm{N}=3055)$.

During the SELFIE workshop, participants from 16 countries agreed that SELFIE reports help the teaching staff to evaluate the progress and results of their work on the DT integration in teaching and learning (Commission, 2019). At the same time, school staff expressed interest in receiving relevant and detailed recommendations to enhance digital transformation of their schools. The paper contributed to the specific recommendations development approach, and assumed an integrative assessment of the specific characteristics with their meaningful interpretation based on quantitative data. Analysis of the SELFIE pilot results has shown that, based on proposed data-driven scales, it is possible to develop the specific recommendations on the formation of a shared vision on the integration of DT in educational process, and the use of innovative teaching and learning with DT. 


\section{INSTRUMENTS DESIGN}

\subsection{A Dichotomous Categorization}

The idea of dichotomous categorization is based on a theoretical grounded scale (Kools \& Stoll, 2016) and on premise, that discussions in the school community serve as a tool to shape a shared vision. The assessment of the nature of such discussions can be treated as an indicator of the extent to which, the formation of a shared vision on the use of digital technologies in teaching and learning is endorsed in a particular school. It can serve as a basis for the development of certain recommendations that are provided as feedback to SELFIE school participants. The dichotomous categorization includes three steps:

1. To build a dichotomous scale, where 0 - shared vision is not shaped, 1 - shared vision is shaped.

2. To conduct a survey. This methodology can use Likert scale data collected from school leaders, teachers and students, with questions on the advantages and limitations of digital technologies (DT) in the classroom, and on the use of DT to enhance the effectiveness of teaching and learning.

3. To determine characteristics. A set of variables is defined as $\left(V_{d,} V_{c}\right)$ (table 1$)$ :

Table 1. Variables and statistical procedures

\begin{tabular}{|c|c|c|}
\hline Variable & Type & Statistical procedures \\
\hline$V_{2}$ & $\begin{array}{l}\text { Binary variable, characterized } \\
\text { the discussion of the } \\
\text { advantages and limitations of } \\
\text { DT in the classroom }\end{array}$ & $\begin{array}{ll}\text { 1. } & \text { Levene's test } \\
\text { 2. } & \text { Kruskal-Wallis H-test } \\
\text { 3. } & \text { Post-hoc Dunn's test }\end{array}$ \\
\hline$v_{\mathrm{L}}$ & $\begin{array}{l}\text { Binary variable, characterized } \\
\text { the use of DT to enhance the } \\
\text { effectiveness of teaching and } \\
\text { learning }\end{array}$ & $\begin{array}{l}\text { 1. Levene's test } \\
\text { 2. Kruskal-Wallis H-test }\end{array}$ \\
\hline
\end{tabular}

4. To categorize variable states. When both $V_{\leftarrow}$ and $V_{c}$ showed that there is no consistent difference in responses, it is treated as "Shared vision on DT in teaching and learning is shaped", otherwise it is treated as "Shared vision on DT in teaching and learning is not shaped".

\subsection{A K-Mode Clustering Algorithm with Qualitative Validation}

The idea of a combined procedure is based on the interpretation of quantitative data obtained after cluster analysis of a survey of teachers and school leaders (Vodopian and Uvarov, 2005), and the concept of the stages of development (maturity) of the school informatization (Lee and Broadie, 2016). It allows the matching of data on the use of innovative teaching and learning with DT, and judgments based on maturity models of the innovative processes in the school. The combined procedure includes four steps.

1. To conduct a survey in order to collect the data for further analysis. This methodology can use survey five-point Likert data collected, from at least two cohorts of actors of educational process, wherein a survey contains an item on innovative DT-supported teaching and learning.

2. To determine characteristics. For each school, a group of characteristics is calculated that reflects whether a school is working, both consistently and constantly on the use of innovative DT-supported teaching and learning. A set of variables defined at school level:

\section{(SL consens!s, $\left.S L_{\text {cohersnces }}, T_{\text {consenzuz, }} T_{\text {cokerence }}\right)$}

$S L_{\text {consenss }}$ - how coordinated are the efforts of school leaders to use innovative DT-supported teaching and learning;

$S L_{\text {coherexc }}$ - how consistent are the efforts of school leaders to use innovative DT-supported teaching and learning;

$T_{\text {consemses }}$ - how coordinated are the efforts of teachers to use innovative DT-supported teaching and learning at school level;

$T_{\text {colicrsnce }}-$ how consistent are the efforts of teachers to use innovative DT-supported teaching and learning at school level. 
To determine the value of consistency variables, the proportions of positive answers ("agree" and "absolutely agree") are calculated for each group of respondents. If at least $60 \%$ of positive answers, the value of both variables is fixed as "high". Otherwise, it is fixed as "low". When determining the value of coordination variables, a standardized characteristic is calculated - a measure of variability (Allaj, 2018). The meaning of the coordination of efforts is evaluated as "low" if the variability measure of answers is far from 0.553 or 1 , and "high" when the measure of the variability of answers is close to 0.553 or 1 .

3. To cluster schools. The k-mode clustering algorithm is applied. When choosing the number of clusters, one uses qualitative descriptions of the resulting clusters after calculating the optimal number of clusters (using the elbow method). Here, one evaluates clusters in terms of significant differences in the use of innovative DT-supported teaching and learning at school level.

4. To correspond the cluster structure against maturity levels. At this step the resulting cluster structure is corresponded to the maturity scale of the innovation process by expert evaluation. We use the five-level scale of the innovation process maturity model of RISC model (DeLorenzo and Battino, 2008).

\section{RESEARCH RESULTS}

\subsection{A Shared Vision on the Integration of DT in Educational Process}

To assess a shared vision on the integration of DT based on the technique proposed, we used two triads of items of "Leadership and Management" component of the DigCompOrg framework (Dvoretskaya, 2018):

- Items on the discussion of the advantages and limitations of DT in the classroom, were coded as L1, $\mathrm{T} 1$, and S1 for school leaders, teachers, and students, respectively.

- Items on the use of digital technology to enhance the effectiveness of teaching and learning, were coded as L2, T2, and S2 for school administrators, teachers, and students, respectively.

Statistical results evidenced that respondents differ in how they view the advantages and disadvantages of digital technologies in teaching and learning $(\mathrm{p}=0.000)$, and at the same time, they agree that it is desirable to use digital technologies in schools to improve the effectiveness of teaching and learning (table 2).

Table 2. Statistical results

\begin{tabular}{llllll}
\hline & \multicolumn{2}{l}{ Levene's test } & \multicolumn{2}{l}{ Kruskal-Wallis H test } \\
\cline { 2 - 6 } & $\mathrm{F}$ & $\mathrm{p}$ & $\mathrm{H}$ & $\mathrm{p}$ \\
\hline School leaders, teachers, and students & 7,38 & $0,000 * * *$ & 20,58 & $0,000 * * *$ \\
\hline L1, T1, S1 & 5,91 & $0,003 * *$ & 0,003 & 0,998 \\
L2, T2, S2 & & & & \\
\hline Significance levels: $* * \mathrm{p}<0.01 . * * * \mathrm{p}<0.001$. & & & & \\
\hline
\end{tabular}

As the Dunn's test shows, there is a statistically significant difference in the positions of the three groups of respondents regarding the discussion of the advantages and disadvantages of using digital technology in school. Categorizing results, we can conclude, that the shared vision needs to be developed.

\subsection{The Use of Innovative Teaching and Learning with DT}

To assess the use of innovative teaching and learning with DT, we used the combined technique in the processing of school principals $(\mathrm{N}=206)$ and school teachers $(\mathrm{N}=685)$ in SELFIE. The distribution of schools, according to clustering, showed that all schools already realized the need to use innovative DT-supported ways of teaching and learning. However, schools organize this work in different ways (table 3). 
Table 3. School cluster structure against RISC maturity levels

\begin{tabular}{lll}
\hline Level of RISC scale & Clusters & Number of schools \\
\hline Awareness & $2,3,6,7,8,9$ & 16 \\
Understanding & 1,5 & 5 \\
First implementation & 4 & 2 \\
Usage & - & - \\
Elaboration & - & - \\
\hline
\end{tabular}

All schools are at least introducing innovative DT-supported teaching and learning. In most schools (the level of "Awareness"), the corresponding processes are ad-hoc. Individual teachers and / or school leaders initiate the use of innovative DT-supported teaching and learning here. One can distinguish a group of schools in which the use of innovative teaching and learning, using DT, has become manageable (the level of "Understanding"). In two schools (the level of "First implementation" on the scale), a manageable process has already been established for the implementation and use of innovative DT-supported ways of teaching and learning with a solid and systematic support of it.

\section{CONCLUSION}

The results of the assessment of two parameters, obtained using the procedures described, were discussed with SELFIE school coordinators, involved in piloting, during aftermath interviews and feedback collection. As these discussions have shown, additional feedback prepared in this way, enriches the computer generated basic SELFIE reports significantly. School coordinators and school teams found out that detailed and targeted recommendations on the formation of a shared vision and DT supported innovative teaching, can endorse digital transformation processes in their schools. Computations based on the procedures given above can be fully automated with the recommendations obtained that will be reverted to schools.

In future work, it will be required to check the validity of the developed procedures on sufficient sample size, reflecting the diversity of schools that participate in SELFIE. At the same time, it is necessary to prepare detailed guidelines for school teams that will help them, in cooperation with local communities, to interpret the results of SELFIE obtained together with targeted recommendations.

\section{ACKNOWLEDGEMENT}

The reported study was funded by RFBR, project number №19-29-14167. The authors would like to thank Prof. Alexander Khoroshilov, who initiated the piloting SELFIE in Russia, Marina Korobeinikova from UNESCO IITE, who led the piloting and Dr. Panagiotis Kampylis from EC JRC for the collaboration.

\section{REFERENCES}

Allaj, E. (2018) 'Two simple measures of variability for categorical data', Journal of Applied Statistics, 45(8).

Commission, E. (2019) SELFIE Forum - teaching and learning in the digital age, 4-5 April 2019, Madrid.

DeLorenzo, R. A. and Battino, W. (2008) Delivering on the Promise: The Education Revolution. Solution Tree.

Dvoretskaya, I. V. (2018) 'O sformirovannosti obshchego videniya na ispol'zovanie IKT v uchebnoj rabote $v$ shkole', Nauka i shkola, 5

Kampylis, P., Punie, Y. and Devine, J. (2015) Promoting Effective Digital-Age Learning - A European Framework for Digitally-Competent Educational Organisations. Luxembourg: Publications Office of the European Union.

Kools, M. and Stoll, L. (2016) 'What Makes a School a Learning Organisation?' (137).

Lee, M. and Broadie, R. (2016) 'A Taxonomy of School Evolutionary Changes: Evolution within the Threads', Igarss

Munoz Castano, J. et al. (2018) 'Within-School Differences In The Views On The Use Of Digital Technologies In Europe: Evidence From The Selfie Tool', in EDULEARN18

Vodopian G., Uvarov, A. (2005) Ob odnom instrumente dlya ocenki i upravlenyia razvitiem processa informatizacii shkoly’ // Voprosy obrazovanyia, №3, 2005. Available at: https://vo.hse.ru/2005--3/27044397.html 